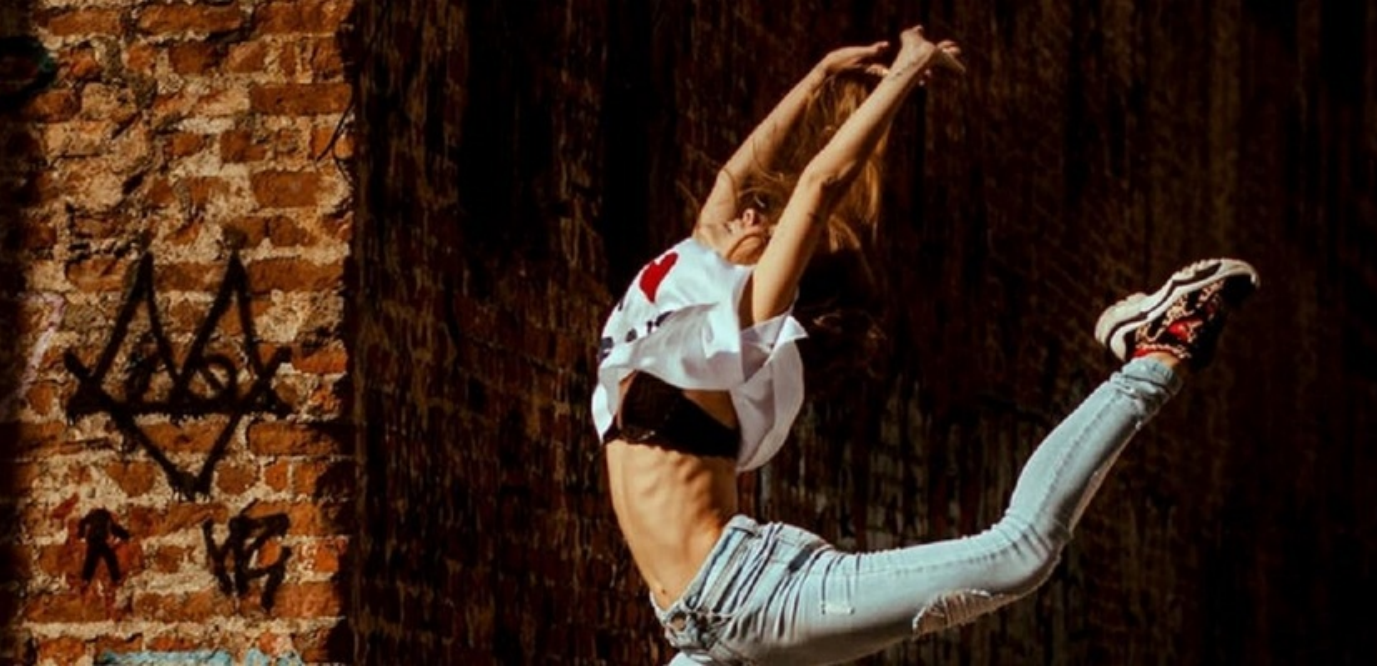

Stage fright - blessing or curse?

Authors: Franziska Buttgereit

Submitted: $\quad$ 18. March 2020

Published: 20. March 2020

Volume: 7

Issue: 2

Affiliation: Theater Freiburg

Languages: English

Keywords: $\quad$ music world, classic music, culture, singing opera, perfoming.

Categories: Performing Arts, Music

DOI: $\quad$ 10.17160/josha.7.2.645

Abstract:

Whether it be a surgeon or a performing artist, most people experience stage fright at some point in their lives. Varying levels of anxiety put stress on the body and impact one's ability to perform, however the ability to cope with a given situation leads directly to positive or negative outcomes.

JOSHA

josha.org

Journal of Science,

Humanities and Arts

JOSHA is a service that helps scholars, researchers, and students discover, use, and build upon a wide range of content 


\title{
JOSHA
}

Journal of Science, Humanities and Arts

\section{Stage fright - blessing or curse?}

\author{
„... Can you perform under pressure? ... \\ No, but I can try Bohemian Rhapsody..."
}

\begin{abstract}
Whether it be a surgeon or a performing artist, most people experience stage fright at some point in their lives. Varying levels of anxiety put stress on the body and impact one's ability to perform, however the ability to cope with a given situation leads directly to positive or negative outcomes.
\end{abstract}

\section{BY FRANZISKA BUTTGEREIT}

Who among us has not been overcome by the feeling of inexplicable fear? The feeling that you cannot handle a situation or that you won't succeed? These feelings often go hand in hand with stomach pain, sweating, rapid heartbeat, nervousness, and/or the irrepressible desire to escape the situation. Hardly anyone is immune from getting into such a situation at least once in their lifetime, whether it be from a test, a lecture, or a public appearance. This fear - stage anxiety (also commonly known as stage fright) - is not innate, rather it is formed from one's own individual experiences, and it arises, among other things, from a confusing situation, from strangers, from the desire not to make any mistakes, and/or from the lack of positive encouragement from caregivers. But when 
does stage fright become a real threat, or even a pathology, which in a worst case scenario would result in one leaving his/her profession?

It is obvious that a certain amount of adrenaline is necessary to be able to master certain situations. Without anxiety - which in turn means energy and intensity - an artist will find it more difficult to captivate and inspire an audience. Stage fright, if it remains within a certain framework, usually has a stimulating effect on the willingness to perform, and it can lead to an increase in strength, contribute to the sharpness of thoughts, and create clarity.

There is no such thing as a perfect performance, and the unrealistic expectation of giving one may increase psychological pressure, causing fear and tension. Mistakes are a natural part of music making.

Every appearance is an adventure, and adventures are inherently risky. Nevertheless, excessive fear can be a burden, which may cause the nervous system certain to stop motor processes, leading to further errors. Stomach pain, tinnitus, and a racing heartbeat, to name just a few symptoms, can be natural overreactions.

All of these symptoms mean only one thing for the body: stress! But what does stress do to us and our health? When under stress, hormones such as adrenaline, noradrenaline and cortisol are released into the blood vessels as messenger substances. The sympathetic nervous system sends signals through the autonomic nerves to the adrenal glands, which then release adrenaline. While the parasympathetic nervous system (antagonist) is inhibited, regeneration and reproduction enzymes are blocking the degradation. The information processed in the brain changes, so muscles, circulation and breathing are ultimately affected. The body begins to produce more energy in order 
to be more efficient in the short term, while at the same time, blood flow is redistributed, and all functions that are not necessary at that moment are inhibited. The involuntary reactions in the body can sometimes lead to noticeable changes in body awareness. The simple fear of it happening again would be enough to trigger the reaction cycle again $=>$ The fear of fear.

This "warning reaction", if it occurs briefly, is harmless, even desirable, in order to be particularly efficient in certain situations, and to master special or challenging requirements. Breathing is increased. The energy sources in the blood vessels are increased => sugar (glucose) and fat (triglycerides and cholesterol) are quickly available and high in energy, from which energy is generated in the cells. The pancreas releases more insulin to transport glucose into the cells.

The feeling of "soft knees", cold fingers or the well-known ,frog in the throat" is the result of the increased blood flow to the muscles due to the stress. There is increased blood flow to the skin, which is usually noticeable as a red face or rosy cheeks or through sweating, since the heat produced by the muscles is conducted to the surface - and the evaporation chill which arises during sweating is used for cooling. The goal of the body is to cut back all metabolic processes that are temporarily "unnecessary" in this state of emergency, by reducing the blood supply to the internal organs. Symptoms are usually noticeable with the associated appearance of a strange feeling in the stomach area, nausea, and in some cases even the reaction to it with diarrhea or increased urination. The blood supply to the cerebrum is also reduced, which means that schematic decision-making patterns in the lower brain regions are called up, and the relatively slow stimulus processing in the cerebrum is suppressed. One's reactions and decisions are more problem-oriented and faster, but still with higher error rates. In extreme cases, this condition can lead to loss of consciousness, dissociation, complete mental immobility or, in very rare cases, even death due to shock. However, there are usually harmless signs such as a feeling of terror, fear, dizziness or panic, or the difficulty to concentrate. 
Even the perception of pain diminishes, since the simultaneous sensation of pain in a stressful situation could represent a crucial gap in the defense. However, in the long term, a permanent shutdown of this important reporting system of internal imbalance would be dangerous.

A distinction must be made between "stressor" = stress trigger and the "stress reaction".

Stressor is a stress-generating stimulus that can be triggered by anything and everyone at any time, provided the organism considers it to be significant or even threatening. Sometimes just imagining or expecting it is enough to trigger such a reaction.

A stress reaction is the organism's response to the stressor. This reaction allows the body to react energetically and quickly to potential dangerous situations. This process is a physical - mental state with increased short-term vigilance and increased ability to solve problems.

It is always important for everyone to find the right balance between challenge and stress, curiosity and fear, safety and risk ... for themselves and for the situation. If this is not feasible, we experience stress or the effects of the subsequent automatically triggered backup reactions. The stress consequence can be both positive and negative. Positive in the sense of a better adaptation to existing conditions or the creation of more suitable conditions (= successful development).

The negative consequence would be an increased load / overload, which in turn can damage the nervous system.

All symptoms prompt you to continue looking for the triggering condition or for an improved solution. In the short term and at first glance, pseudo-solutions appear to be 
useful, but are not in the long term, since they only work in our imagination (inner reality), leading to resistance. A change of the external reality is not guaranteed. As a result of this, the inner pressure pushes more and more to compensate, the symptoms can worsen or even new symptoms might appear, ending in a shift of symptoms.

The body learns to adapt the internal or external environment to the changed situation, whereby the initial symptoms of the alarm reaction disappear completely, known as adaptation. If this condition persists without the system adapting to the environment or establishing a new equilibrium, this leads to the exhaustion of the system in which adaptive disorders arise.

Adaptation diseases include Hypertension, heart attack, vegetative dysfunction, Crohn's disease, nervous exhaustion and even depressive moods.

The claim to be perfect or the desire to do everything immediately can be overwhelming. They function as stressors, which activate the body again and again unconsciously and thus put them in a constant willingness to act to permanent stress. In therapy, it helps to have the courage to try something new, by breaking old habits. Breathing exercises and meditation are known to calm the symptoms down by keeping the adrenaline input at bay. Other helpful stress releasing techniques include the following: muscle relaxation (physical exercises or massages), reflection upon the actual problems and occurring symptoms, mindfulness-based stress reduction, and autogenic training.

Stress and stage fright is more or less present in most of our jobs or daily routines. 
When and how have you experienced performance anxiety in your job? What was your experience and how did you overcome it?

Does anxiety help or hinder your ability to do your job?

\section{Gynecologist Stephen K. (70)}

I experience stress all the time, but one particular example I can remember is when I was doing surgery with a resident. During surgery, you just have to understand the situation. The main thing is to remain calm and realize that you are "in charge." It was a laparoscopic tubal ligation, and the resident was having trouble inserting the trocar (goes through the belly button- umbilicus) and all of a sudden, blood started coming through and the anesthesiologist said he couldn't get a blood pressure. So, obviously, there was stress and anxiety, but I told the resident that I was going to take over and I basically made a large incision to find out where the bleeding was coming from. The belly was filled with blood, but we cleaned it out and were able to identify the bleeder- it was a major blood vessel that got lacerated while he/she was trying to insert the trocar. At this point, we realized we needed a vascular surgeon, so we got the patient stabilized, controlled the bleeding, and waited for everyone to get there. The patient did fine post operatively, but it was obviously extremely stressful.

Then there's the "day to day" of patients; results, making sure you don't miss anything, etc. There were Obstetrical emergencies, of course. I think it's just the idea that, knowing if you miss something, the consequences can be pretty serious. I'll think did I get this right, that right? Then I'll see the results and that I'm right. I feel relief, but it takes a toll.

As far as taking a physical toll, I think it definitely does. But I guess that's why I am the way I am. I think it's more the emotional toll. It's why sometimes I maybe wasn't as patient 
at home as I should have been; why maybe I act a little silly when I'm not working, as it helps me relieve some tension; maybe that's why I cry so easily at movies.

The main thing is, just like a singer practices, the more experience with things like that, the more comfortable you are with things when they come up. That's why training at a place like Jackson (Memorial) in Miami was so important - I always say that if I didn't see it there, it didn't happen. Even with all my years, all my experience, and the fact that I feel that I always feel I do everything I can to give my best, there is always the worry that something could get missed. I think if you don't feel that way, you aren't caring enough.

\section{Lawyer Laura P. (30)}

Yes, especially before court hearings or important meetings, I get a little frightened. I then worry that I am not sufficiently prepared, that I am unable to do justice to the responsibility that I was given or that I cannot answer questions. Since there is no way to "escape" the situation, I just try to prepare myself well enough and don't think through too many hypothetical situations in my head. I find it best to think in an efficient and clear structure, then I just let it happen and do my best. In most cases, there are many unwarranted worries in advance.

Too much stage fright leads me into a thinking barrier. Up to a healthy degree stress tends to promote my concentration and increases my performance. I would say that I control my stage fright well so that it is not an obstacle in everyday work.

Opera singer Martin M. (51) 


\section{JOSHA}

Journal of Science, Humanities and Arts

I get nervous every time I go on stage to perform. The first few notes are the hardest, I feel the heat, the sweat, luckily my face doesn't turn too red. After a few phrases have been sung, I usually notice the adrenaline to push my performance up. Most of the time for the better, but I had a few off moments as well. Once I forgot my text all of a sudden, the other time I nearly fell off the stage. It's always a useful experience for me. I try to be prepared for each show and situation. Despite all, it never shows any pathetic pattern, but I do have colleagues who struggle a bit. You see them walking up and down, breathing in and breathing out a lot, always avoiding the contact.

But all the stress and anxiety helps me to be aware of the situation and be ready. I try to focus on relaxed lungs by taking some deep breaths before each performance.

\section{About the author:}

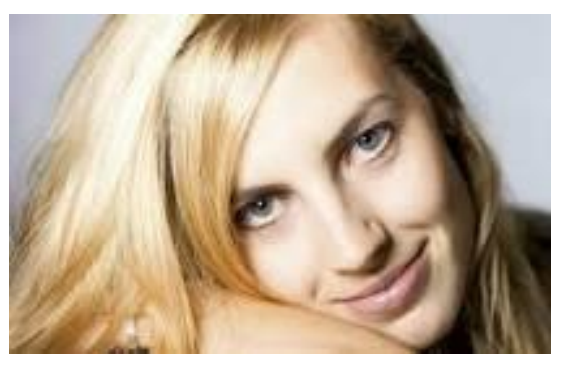

Franziska Buttgereit (mezzo-soprano) received the 1st Federal Prize in the Early Music category in 2007 as well as the Special Prize of the Manfred Vetter Foundation and the 2nd Prize for Early Music at the Handel Competition in Karlsruhe.

Further competitions and prizes in the singing category followed. These prizes brought Franziska to Lübeck for masterclasses with Prof. Christiane Hampe and Michael Gehrke. 2010 she joined the extra choir of the Theater Freiburg and became the first member of the board of directors of the Theater Freiburg. 2015 she started her singing studies with Prof. Christiane Libor at the Musikhochschule Schloss Gottesaue in Karlsruhe. To this day she has collaborated with the University of Music and the Freiburg City Theatre, which has led to a small role in performances and the DVD production of the same name "Cendrillon" by Jules Massenet. In addition to her performances on the music theatre 
Journal of Science, Humanities and Arts

stage, Franziska Buttgereit is passionately devoted to the oratorio and concert repertoire, with which she regularly performs as a soloist. 